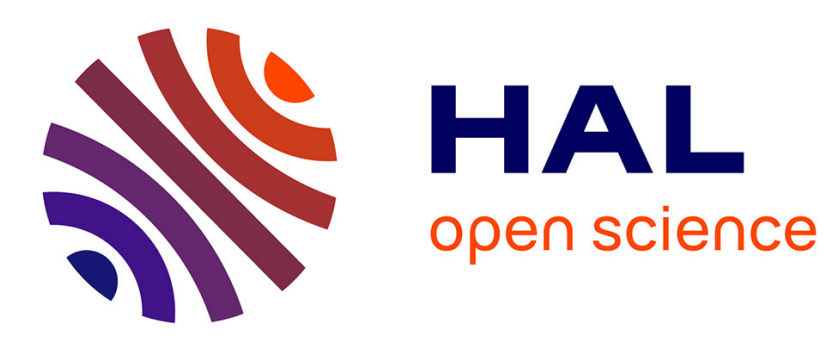

\title{
The role of sonority profile and order of place of articulation on gestural overlap in Georgian
}

Caroline Crouch, Argyro Katsika, Ioana Chitoran

\section{To cite this version:}

Caroline Crouch, Argyro Katsika, Ioana Chitoran. The role of sonority profile and order of place of articulation on gestural overlap in Georgian. Speech Prosody 2020, May 2020, Tokyo, Japan. 10.21437/speechprosody.2020-42 . hal-03127480

\section{HAL Id: hal-03127480 \\ https://hal.science/hal-03127480}

Submitted on 1 Feb 2021

HAL is a multi-disciplinary open access archive for the deposit and dissemination of scientific research documents, whether they are published or not. The documents may come from teaching and research institutions in France or abroad, or from public or private research centers.
L'archive ouverte pluridisciplinaire HAL, est destinée au dépôt et à la diffusion de documents scientifiques de niveau recherche, publiés ou non, émanant des établissements d'enseignement et de recherche français ou étrangers, des laboratoires publics ou privés. 


\title{
The role of sonority profile and order of place of articulation on gestural overlap in Georgian
}

\author{
Caroline Crouch ${ }^{1}$, Argyro Katsika ${ }^{1}$, Ioana Chitoran ${ }^{2}$
}

${ }^{1}$ University of California, Santa Barbara

${ }^{2}$ Université Paris Diderot

crouch@ucsb.edu, argyro@ucsb.edu, ioana.chitoran@univ-paris-diderot.fr

\begin{abstract}
Sonority sequencing principles can account for phonotactic processes across languages, but the articulatory correlates of sonority are not well established. This study examines the relationship between gestural overlap and sonority shape for relationship between gestural overlap and sonority shape for
two-consonant onsets in Georgian via electromagnetic two-consonant onsets in Georgian via electromagnetic articulography. We cross three sonority shapes (rise, plateau, front), since the latter has been shown to affect overlap. The degree of plateau overlap and relative overlap for the consonant gestures are evaluated.

Both sonority shape and order of place of articulation are found to affect overlap. Importantly, in order to understan how Georgian organizes onsets of different sonority shapes we must look at both measures of overlap. The plateau overlap measure reveals that all Georgian clusters present a lag between achieved constrictions; we argue that this languagespecific setting allows for a wider range of consonant sequences to be perceptible. In parallel, the overall overlap measure shows that sonority falls are more overlapped during the formation phase of the second consonant's constriction, which presumably compensates for the later plateau lag and ensures tautosyllabic parsing of the clusters' consonants in sonority falls. Finally, front-to-back clusters are less overlapped than back-to-front clusters across all sonority shapes.

Index Terms: sonority, place of articulation, syllable
\end{abstract} structures, gestural overlap, Georgian

\section{Introduction}

Sonority and theoretical principles emerging from it - e.g., the Sonority Sequencing Principle (SSP) - can be invoked to meaningfully explain phonological and phonotactic processes across languages [1]. However, phonetic correlates of sonority, with the exception of intensity [2], are not well established, and many languages permit sonority 'violations' especially in syllable onsets [3][4]. Here, we examine the relationship between the sonority shape of a syllable onset and the degree of overlap between the constituent consonan gestures. The goal of this study is to understand how Georgian, a language that allows sonority reversals and plateaus in word onsets, simultaneously maintains a balance between perceptibility of members of a cluster and a tautosyllabic parse of the same cluster.

Since sonority plateaus and falls do exist, there must be some mechanism by which they ensure that cues for their constituent segments are preserved and their segmental makeup is recoverable. Decreased overlap can play an important role in ensuring the recoverability of some segments; for example, in stop-stop sequences decreased overlap allows for both stops to have a release burst, preserving crucial place cues for the first stop [5] [6]. Acoustic work on Georgian clusters found distinct closures and releases for both members of two-consonant clusters [7]. However, decrease in overlap was found in [8] even in sonority rises, so we should consider it not to be directly related to sonority but to order of place of articulation and perhaps also to segmentinternal properties like coarticulation resistance [9][10][11][12]. For this reason, in our study we also control for order of place of articulation within the onset cluster.

\subsection{Sonority}

Sonority is an abstract property of speech sounds whose physical correlates have not been fully determined. Acoustically, intensity has been established as the most reliable correlate of sonority [2]. Constriction degree - and the related but not entirely dependent jaw openness - is a possible articulatory correlate of sonority, but there are problems with this hypothesis. First, we know that articulatory factors beyond constriction degree play a role in jaw height [13][14][15]. Second, different languages permit different phonotactic behavior in segments that are otherwise very similar. Recent work [16][17] provides evidence that language-specific overlap patterns could drive these different phonotactic behaviors.

In this study we use the following sonority scale, adapted from [18]:

vowel $>$ glide $>$ liquid $/$ nasal $>$ fricative $>$ stop

The scale is broad enough that it can be used to analyze a variety of phenomena across many languages. Language specific rules relating to sonority are often invoked, and we have designed our stimuli (section 3.1) to avoid sonorityambiguous clusters. This is to maximize the predictive ability of this work in a typological perspective.

\subsection{Overlap}

Overlap between consonants is both language-specific [16][17] and determined by a variety of factors [17][19]. Order of place of articulation affects degree of overlap; research on Georgian [4], French [20] and Korean [21] has shown that back-to-front clusters are less overlapped than front-to-back clusters. The voicing status of cluster members has also been hypothesized to affect overlap [17]. In general, the identity of each consonant in the cluster could affect 
degree of overlap; this is also related to coarticulation resistance [9][10][11][12].

Work on German has found that stop-nasal clusters and stop-liquid clusters display different patterns of overlap and are differently affected by changes in voicing status of the obstruent member of the cluster [17]. Further work on German reveals a hierarchy of overlap in different clusters that seems to rely on a variety of factors including manner and order of place of articulation; $/ \mathrm{kl} /$ has the most overlap, followed by $/ \mathrm{pl} />/ \mathrm{ps} />/ \mathrm{ks} />/ \mathrm{kn} /[19]$.

Our study contributes to the understanding of overlap and what influences it by controlling not only for order but for sonority profile as well, which to an extent acts as a proxy for manner. We also take two measures of overlap in order to make this work comparable to a wider range of research on other languages and to understand how different factors may influence different types of overlap between segments.

\subsection{Hypotheses}

H1: Back-to-front clusters will be less overlapped than front-to-back clusters.

Previous research on Georgian has shown this to be the case [8].

H2: Degree of overlap in sonority rises will be the least affected by order of place of articulation.

Sonority rises are the most common type of sonority shape cross-linguistically, and we hypothesize that this is related to their relative articulatory stability. In the context of this experiment, this means that order of place of articulation will have the least effect on degree of overlap in sonority rises, as compared to sonority falls and plateaus.

\section{Methods}

We report here on a pilot experiment involving one female participant in her twenties, who is a native speaker of Tbilisi Georgian.

\subsection{Stimuli and experimental design}

Stimuli are presented in the table below. Each word was produced eight times in the carrier phrase $k^{\prime} i d e v$ ('I said again' for a total of 112 tokens.

\begin{tabular}{|l|l|l|}
\multicolumn{2}{c|}{ Table 1: Test words organized by experimental factor } \\
\hline & Front to back & Back to front \\
\hline Sonority rise & $\begin{array}{l}\text { brelo 'chaff' } \\
\text { p'ledi 'rug' }\end{array}$ & $\begin{array}{l}\text { tmaze 'hair.in' } \\
\text { dmanisi (place) }\end{array}$ \\
\hline Sonority plateau & $\begin{array}{l}\text { mnaxe 'see' } \\
\text { bk'ichi 'raisin' } \\
\text { bgera 'sound' }\end{array}$ & $\begin{array}{l}\text { t'baze 'lake.in' } \\
\text { k'bili 'tooth' } \\
\text { kbena 'sting' }\end{array}$ \\
\hline Sonority fall & $\begin{array}{l}\text { mtaze 'mountain.in' } \\
\text { mdare 'worthless' }\end{array}$ & $\begin{array}{l}\text { rbena 'running' } \\
\text { lp'eba 'decaying' }\end{array}$ \\
\hline
\end{tabular}

The stimuli above cross three levels of sonority shape with two levels of order of place of articulation. Front-to-back rise onsets are the exact reverse of the back-to-front sonority fal onsets, and the same is true from front-to-back sonority falls and back-to-front sonority rises. Sonority plateaus of different orders also exhibit this pattern where possible.

\subsection{Data acquisition}

Data were collected using an Electromagnetic Articulograph AG501 (Carstens Medizinelektronik GmbH). Sensors were attached at three points along the tongue (two on the tongue body, one on the tongue tip); on the upper and lower lip; on the upper and lower incisor; and on the bridge of the nose and behind each ear. The participant read the stimuli off of a computer screen placed approximately three to four feet from the EMA. Audio was recorded with a Shure SCM262 microphone mixer at a $16 \mathrm{kHz}$ sampling rate, with a Sennheiser shotgun microphone positioned a foot away from the participant's mouth. Kinematic data was automatically synchronized with the external audio data.

\subsection{Analysis}

Data were semi-automatically labelled using custom software (Mark Tiede, Haskins Laboratories). Specifically, the gestures [22] for the two onset consonants were detected, and the following kinematic timepoints were identified based on velocity criteria; onset, peak velocity, plateau onset (target), constriction maximum and plateau offset (release) of the constriction maximum and plateau offset (release) of the
gesture's formation, and peak velocity and offset of the gesture's release (see Figure 1). Labial, coronal and dorsal consonants were labeled on the lip aperture, tongue tip vertical displacement and tongue dorsum vertical displacement trajectory respectively. The labelled timepoints were then used to calculate overlap, as discussed below.

Two measures of overlap were calculated for all onsets. The first measures the relative temporal distance between the target achievement of the first consonant and the onset of the second consonant [4][23].

$\underline{\left(C_{2} \text { Onset }\right)-\left(C_{1} \text { Plateauonset }\right)}$

The second is a measure of the overlap between the plateaus of the two consonant gestures [24].

$$
\frac{\left(C_{1} \text { PlateauOffset }-C_{2} \text { PlateauOnset }\right)}{\left(C_{1} \text { PlateauOnset }-C_{2} \text { PlateauOffset }\right)}
$$

Higher positive values for relative overlap (1) indicate more temporal overlap between the two consonants. Negative values for this measure would mean that the second consonant began before the first consonant reached its target. Positive values for plateau overlap (2) indicate overlap between the plateaus; the higher the value the higher the degree of overlap. Negative values for plateau overlap (2), like those reported below, indicate plateau lag; the first consonant's release has already begun by the time the second consonant achieves its target. More negative values indicate greater lag.

The figure below shows example labels for the word rbena. The yellow bar shows the tongue tip (TT) gesture for [r] , and the black bar below shows the labial gesture (LA) for [b]. The shaded portion of each bar represents the gestural plateau. The relevant landmarks are labelled as follows: (1) 
marks the gestural onset; (2) the plateau onset/achievement of target; (3) plateau offset/target release; and (4) gestural offset. sonority plateau-indicate that the second consonant began before the first reached its target.

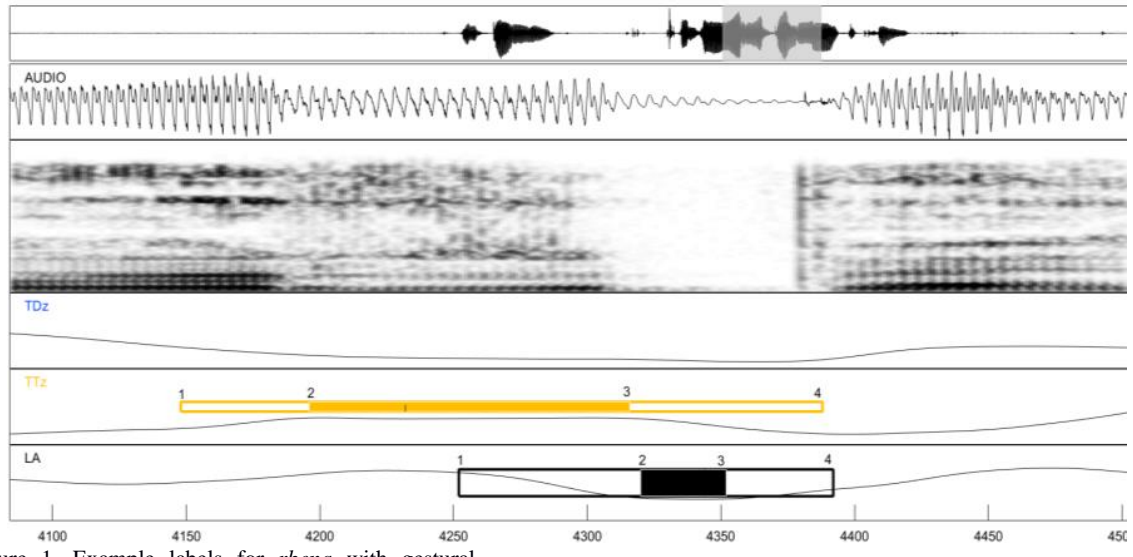

Figure 1. Example labels for rbena with gestural timepoints labelled: gestural onset (1), plateau onset/target (2), plateau offset/release (3), and gestural offset (4)). $/ \mathrm{r} /$ is labelled on the tongue tip vertical displacement $(\mathrm{TTz})$ trajectory, and $/ \mathrm{b} /$ on the lip aperture (LA) trajectory.

Data were analyzed in R [25] using a linear mixed effect model for each measure with Order of place of articulation, Sonority shape, and their interaction as the fixed effects and Sonority shape, and their interaction as the fixed effects and
Word as a random effect. Post-hoc pairwise comparisons were performed using R's relevel function, with a Bonferroni correction compensating for each additional evaluation of fixed factors.

\section{Results}

Analysis shows that order of place of articulation and sonority shape affect both measures of overlap.

\subsection{Relative overlap}

For relative overlap, Order $[\chi 2(3)=14.656, \mathrm{p}<.01)]$, Sonority $[\chi 2(4)=19.61, p<.001]$, and their interaction $[\chi 2(2)=7.655$, $\mathrm{p}<.01)$ are significant in the overall model. The $\mathrm{R}^{2}$ value of the fixed effects is .3 . Once the random effect of Word is included, the $\mathrm{R}^{2}$ value is .42 . The pairwise comparisons revealed that sonority falls and plateaus are significantly different from one another $(\beta=1.86$, s.e. $=.67, p<.05)$. The difference between rises and falls does not quite reach significance $(\beta=1.78$, s.e. $=.73, p=.08)$. Rises and falls are similar in that they are less affected by changes in order of place of articulation. Order is significant within sonority plateaus $(\beta=-2.09$, s.e. $=.6, p<.01)$, but is not significant within sonority falls or sonority rises. Figure 2 below shows these results; lower values indicate higher degrees of overlap. Negative values - which are within the error bar range for sonority falls in both Order conditions and for front-to-back

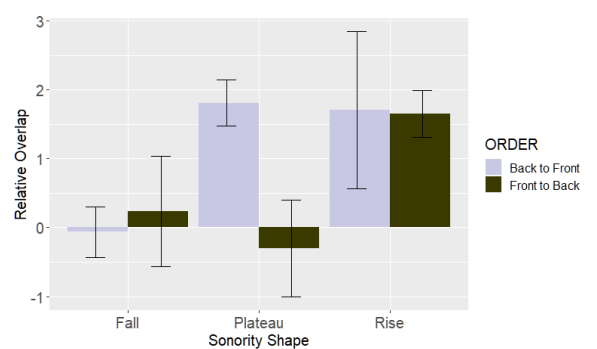

Figure 2. Relative overlap by sonority shape and order of place of articulation

\subsection{Plateau overlap}

For plateau overlap, Order $[\chi 2(3)=18.906, \mathrm{p}<.001)]$, Sonority $[\chi 2(4)=20.028, p<.001]$, and their interaction $[\chi 2(2)=18.563$, $\mathrm{p}<.001)]$ are significant in the model. In all conditions there is $\mathrm{p}<.001)]$ are significant in the model. In all conditions there is
plateau lag. The $\mathrm{R}^{2}$ value of the fixed effects is .34 . Once the plateau lag. The $\mathrm{R}^{2}$ value of the fixed effects is .34. Once the
random effect of Word is included, the $\mathrm{R}^{2}$ value is .47 . According to the pairwise comparisons, sonority falls and rises are significantly different $(\beta=.48$, s.e. $=.16, \mathrm{p}<.05)$ as are falls and plateaus $(\beta=.49$, s.e. $=.15, p<.05)$. Order is significant within plateaus $(\beta=46, \mathrm{~s} . \mathrm{e}=13, \mathrm{p}<01)$, and almost reaches within plateaus $(\beta=.46$, s.e. $=.13, \mathrm{p}<.01)$, and almost reaches
significance for falls $(\beta=-.39$, s.e. $=16, p=.08)$, though the direction of the effect is different; in falls there is more lag in front-back-clusters, while the reverse is true for plateaus. Figure 3 below shows these results. Negative values are found for all combinations of Sonority and Order conditions. Negative values indicate plateau lag, which means that the second consonant plateau does not begin until after the offset of the plateau of the first consonant. Another way of describing this pattern is to say that the second consonant does not reach its target until after the release of the first consonant. 


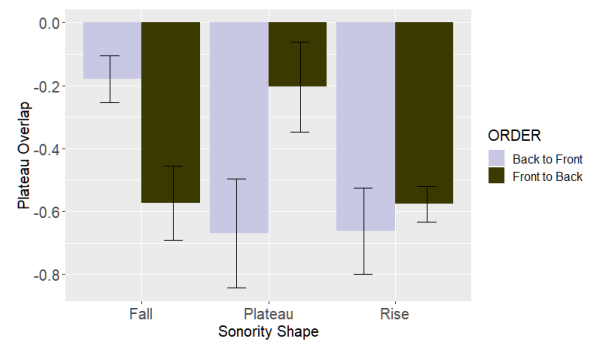

Figure 3. Plateau overlap by sonority shape and order of place of articulation

\section{Discussion}

These preliminary data confirm our second hypothesis that overlap in sonority rises will be least affected by order of place of articulation. Order of place of articulation had no place of articulation. Order of place of articulation had no
significant effect on either measure of overlap for sonority rises. With respect to both measures of overlap, sonority rises are more stable - that is, they are not significantly affected by order of place of articulation - than sonority plateaus, and more stable than sonority falls with respect to plateau overlap. If we consider sonority rises to be the "default" sonority shape by virtue of their being the most common cross-linguistically, then we can confirm previous conclusions [5] that the "default" pattern of overlap in Georgian onsets is one of low overlap, both between consonant plateaus and with respect to the onset of the second consonant relative to the target achievement of the first.

Our first hypothesis, that back-to-front clusters will be less overlapped than front-to-back clusters, was only partially confirmed. For both measures back-to-front clusters were significantly less overlapped only for sonority plateaus. The other significant effect of order within a sonority shape was in the opposite direction; back-to-front sonority falls had significantly less plateau lag, i.e. were more overlapped, than their front-to-back counterparts.

That only sonority plateaus fully conformed to this hypothesis is not entirely unexpected. Five of the six sonority plateaus in the experiment are sequences of two oral stops which both require an audible release to be maximally perceptible. Previous studies that found this effect also considered stop-stop sonority plateaus [5]. If the place order effect is driven by perceptibility requirements [5][26], we would not necessarily expect it to be replicated for sonority plateaus of other forms, e.g. fricative-fricative sequences such as $/ \mathrm{sx} /$ or $/ \mathrm{xs} /$, both of which are licit onsets in Georgian, because these consonantal gestures do not involve complete constrictions. Their characteristic formant structure and formant transitions carry acoustic information about their identity, that remains available even at a high degree of overlap. Sonority rises and falls, which involve transitions from one constriction degree to a distinctly different one, are also not expected to have this restriction. One study [26] did report a place order effect for stop-liquid and liquid-stop sequences, but it was based on kinematic data from only two native Georgian speakers.
The results from the relative overlap measure (Figure 2) are more unexpected but can tell us a great deal about how Georgian is able to maintain sonority-nonconforming onsets. First, we can attribute the relative stability of sonority falls with respect to this measure to the fact that only one consonant in any of the four clusters requires an audible release burst, as discussed above. Sonority falls were also the most overlapped of any sonority condition on average. We suggest that this could be a mechanism to produce the less sonorous segment closer to the syllable edge. This also has the effect of reducing the likelihood of an intrusive vocoid emerging between the two consonants. The low plateau overlap of Georgian creates opportunities for vocoids and, in fact, intrusive vocoids have been found, both for this speaker in other experiments and in other research on Georgian [8]. However, these vocoids have only been reported in sonority rise and sonority plateau conditions, indicating that long plateau lag in combination with low relative overlap is necessary for vocoids to be realized. Vocoid intrusion can improve perceptibility by allowing for an audible release. This is most crucial for stops, and when a stop is the first consonant in a CC sequence, that sequence is either a sonority rise or a plateau. Stops in CC sonority falls are released into the vowel nucleus, so their perceptibility is not at risk. Conversely, intrusive vocoids can also affect the syllable parse, and we would expect sonority falls - cross-linguistically dispreferred onsets - to be most at risk of being reparsed as two CV syllables. So, the high degree of relative overlap in sonority falls disfavors vocoid intrusion and this in turn may ensure that these sequences are parsed as tautosyllabic.

Looking at the results of this pilot study in their entirety, we can say that overall Georgian is a language that prefers low overlap both between consonant plateaus and between onset and target of two consonants. Where there is overlap it is largely between the plateau of the first consonant in a sequence and the movement to target, also referred to as constriction formation, of the second consonant. This pattern can be seen clearly for the sonority fall in rbena in Figure 1, where the labial gesture reaches its target (timepoint (2) in the LA trajectory) after the TT gesture's plateau for / $r$ / (interval between timepoints (2) and (3) in the TTz trajectory). The result is a system where both members of a cluster are perceptible regardless of their relative sonorities and where sonority-nonconforming clusters are not at risk of being phonologized into CVCV sequences. Data collection and analyses are underway to shed light on these conclusions.

\section{Conclusions}

Our preliminary work on Georgian syllabic structure has found that sonority affects two different measures of overlap, providing support for the hypothesis that sonority can be best understood articulatorily through overlap. We argue that these overlap patterns in Georgian preserve perceptual cues for both members of a cluster and ensure a tautosyllabic parse of sonority-nonconforming consonant clusters.

\section{Acknowledgements}

This work was supported by NSF Grant \# 1551428. We would also like to thank UCSB Phonetics Circle for their valuable feedback. 


\section{References}

[1] G. N. Clements, "The role of the sonority cycle in core syllabification," In Laboratory Phonology, J. Kingston and M. Beckman, Eds. Cambridge: Cambridge University Press, 1990, pp. 283-333.

[2] P. Ladefoged, and K. Johnson, A course in phonetics. Toronto: Nelson Education, 2014

[3] S. G. Parker, The Sonority Controversy. Phonology and Phonetics; 18. Berlin; Boston: De Gruyter Mouton, 2012.

[4] C. Jany, M. Gordon, C. M. Nash, and N. Takara, "How universal is the sonority hierarchy?: a cross-linguistic acoustic study," In Proceedings of the $16^{\text {th }}$ International Congress of Phonetic Sciences, 2007, pp. 1401-1404.

[5] I. Chitoran, L. Goldstein, and D. Byrd. "Gestural overlap and recoverability: Articulatory evidence from Georgian," in, Papers in Laboratory Phonology 7, C. Gussenhoven and N. Warner, Eds. Berlin; Boston: De Gruyter Mouton, 2002, pp. 419-447.

[6] I. Chitoran, "Accounting for sonority violations: the case of Georgian consonant sequencing," In Proceedings of the 14th

[7] I. Chitoran, "Georgian Harmonic Clusters: Phonetic Cues to Phonological Representation." Phonology, vol. 15, no. 2, 1998 , pp. 121-41.

[8] L. Goldstein, I. Chitoran, and E. Selkirk, "Syllable structure as coupled oscillator modes: evidence from Georgian vs. Tashlhiyt Berber," In Proceedings of the 16th International Congress of Phonetic Sciences, 2007, pp. 241-24

[9] M. Pastätter, and M. Pouplier, "Onset-vowel timing as a function of coarticulation resistance: Evidence from articulatory data," In Proceedings of the 18th International Congress of Phonetic Sciences, 2015.

[10] M. Pastätter, and M. Pouplier, "The temporal coordination of Polish onset and coda clusters containing sibilants," In Proceedings of the 10th International Seminar on Speech Production, Cologne, Germany, 5-8 May 2014, pp. 312-315. [11] D. Recasens, "A study of jaw coarticulatory resistance and
aggressiveness for Catalan consonants and vowels," Journal of the Acoustical Society of America, vol. 132, 2012, pp. 412-420.

[12] D. Recasens, M. D. Pallars, and J. Fontdevila, "A model of lingual coarticulation based on articulatory constraints," Journal of the Acoustical Society of America, vol. 102, 1997, pp. 544 561 .

[13] C. Mooshammer, P. Hoole, and A. Geumann, "Jaw and order," Language and Speech, vol. 50, no. 2, 2007, pp. 145-176.

[14] C. Mooshammer, A. Geumann, P. Hoole, P. Alfonso, P. van Lieshout, and S. Fuchs, "Coordination of lingual and mandibular Lieshout, and S. Fuchs, "Coordination of lingual and mandibular
gestures for different manners of articulation," In Proceedings of gestures for different manners of articulation," In Proceedings of
the 15th International Congress of Phonetic Sciences, 2003, pp. the 15th

[15] M. Tabain, "Jaw movement and coronal stop spectra in Central Arrernte," Journal of Phonetics, vol. 40, no. 4, 2012, pp. 551567.

[16] M. Pouplier, "The gestural approach to syllable structure: Universal, language-and cluster-specific aspects," in Speech planning and dynamics, S. Fuchs, M. Weirich, D. Pape, and P. Perrier, Eds. Frankfurt: Peter Lang, 2012, pp. 63-96.

[17] L. Bombien, and P. Hoole, "Articulatory overlap as a function of voicing in French and German consonant clusters," Journal of the Acoustical Society of America, vol. 134, no. 1, 2013, pp. 539-550.

[18] S. G. Parker, "Sonority," in The Blackwell Companion to Phonology, M. van Oostendorp, C. J. Ewen, B. Hume, and K. D. Rice, Eds. New York: Wiley, 2011, pp. 1-25.

[19] L. Bombien, C. Mooshammer, and P. Hoole, "Articulatory coordination in word-initial clusters of German," Journal of Phonetics, vol. 41, no. 6, 2013, pp. 546-561.

[20] B. Kühnert, P. Hoole, and C. Mooshammer, "Gestural overlap and C-center in selected French consonant clusters," 7th International Seminar on Speech Production (ISSP), Dec 2006, Ubatuba, Brazil, pp. 327-334.
[21] M. Son, A. Kochetov, and M. Pouplier, "The role of gestural overlap in perceptual place assimilation: Evidence from Korean," in Papers in Laboratory Phonology 9, Berlin; Boston: De Gruyter Mouton, 2007, pp. 507-534.

[22] C. Browman, and L. Goldstein, "Articulatory gestures as phonological units," Phonology, vol. 6, no. 2, 1989, pp. 201-251.

23] A. I. Gafos, P. Hoole, K. Roon, C. Zeroual, C. Fougeron, B. Kühnert, M. D'Imperio, and N. Vallée, "Variation in overlap and phonological grammar in Moroccan Arabic clusters," Papers in Laboratory Phonology 10, Berlin; Boston: De Gruyter Mouton, 2010, pp. 657-698.

[24] P. Hoole, M. Pouplier, S. Benus, and L. Bombien, "Articulatory coordination in obstruent-sonorant clusters and syllabic consonants: data and modelling," in Rhotics: New data and perspectives, A. Vietti, and L. Spreaficio, Eds. Bozen-Bolzano University Press, 2013, pp. 81-98.

[25] R Core Team, R: A language and environment for statistical computing. R Foundation for Statistical Computing, Vienna, Austria. 2018. URL https://www.R-project.org/.

[26] I. Chitoran, and L. Goldstein, "Testing the phonological status of perceptual recoverability: Articulatory evidence from Georgian," In Proceedings of the l0th Conference on Laboratory Phonology, 2006, pp. 69-70. 